\title{
Discerning Data Analysis Methods to Clarify Agonistic/Antagonistic Actions on the Ion Flux Assay of Ligand-Gated Ionotropic Glutamate Receptor on Engineered Post-Synapse Model Cells
}

Akito Tateishi ${ }^{1}$, Michael Cauchi ${ }^{2}$, Chisato Tanoue ${ }^{1}$, Satoshi Migita ${ }^{1}$, Sarah K. Coleman ${ }^{3}$, Shinya Ikeno ${ }^{1}$, Kari Keinänen ${ }^{3}$, Conrad Bessant ${ }^{2}$ and Tetsuya Haruyama ${ }^{1 *}$

${ }^{1}$ Department of Biological Functions and Engineering, Kyushu Institute of Technology, Kitakyushu Science and Research Park, Fukuoka, 808-0196, Japan 2Cranfield Health, Cranfield University, Cranfield, Bedfoldshire MK43 OAL, United Kingdom

3Department of Biological and Environmental Sciences, Division of Biochemistry, Viikki Biocenter, University of Helsinki, Helsinki, Finland

\begin{abstract}
Cell-based experiments provide the efficacy of chemicals through the biological function. The authors have described post-synapse model cell-based assay based on qualified analysis for neural drug discoveries. However, in general, cell-based assays often include data fluctuation. This may be a barrier preventing the performance for various practical purposes. In this study, we tried discerning data analysis for clarify the chemical action to the ionotoropic glutamate receptor (GluR), whereby an ion-flux assay of post-synapse model cells is performed and are analyzed based on a chemometrics approach. The dynamic behavior of the GluR of post-synapse model cell was assayed with multivariate data analysis methods namely hierarchical cluster analysis (HCA) and principal component analysis (PCA). By using HCA, we can identify and remove the non-responding samples. By using PCA, the effect of chemicals on the dynamic behavior of ion flux through GluR can be recognized clearly; as either agonist or antagonist. As shown in the results, the GluR-based assay by post-synapse model cell with data analysis methods provide a sodium influx profile which is derived by an agonists or antagonists application. By employing the data analysis methods, PCA and $\mathrm{HCA}$, it is possible to develop a smart cellular biosensing system for qualified analysis.
\end{abstract}

Keywords: Cell-based assay; Qualified analysis; Ligand-gated ion channel; Cell-to-cell variation; Principal Components Analysis (PCA); Hierarchical Cluster Analysis (HCA)

\section{Introduction}

Cultured mammalian cells have been employed in many different basic and applied research fields, including some with practical purposes. In most cases, the data from cell-based experiments include fluctuations, which may derive the fettle and plight on the cell, such as the protein expression level, cell morphology, cell cycle or cell viability [1-4]. In many examples of cell-based research, multiple experiments have been performed in order to minimize the range of fluctuation. However, in most cases, multiple experiments do not provide smaller fluctuations. Multiple experiments ignore the effect of the fettle and plight on individual cells. Therefore, some research groups have chosen to measure the dynamic behavior of cellular function. This is because dynamic behavior gives a profile of molecular information in the form of cellular response.

Cellular response is a signal from biological cascades in cellular functions. Hence cellular response has been employed in cell functionality studies. It has also been employed to study qualified analysis based on the cellular responses [5]. Qualified analysis is a way to recognize the efficacy of chemicals on biological cascades in cells based on the measurement of cellular responses, in particular the dynamic behavior. Among the cell based assays, designed smart assay systems, cellular biosensing [6], measures the molecular response to extracellular stimulus (chemical or physical). Many different types of cellular biosensing systems have been reported [7-11]. However, the biosensing data from these cultured cell-based systems typically contains data fluctuations. This is a barrier that prevents researchers from discerning the molecular information from cell-based assay methods such as cellular biosensing.

Nevertheless, demands for the method of cellular biosensing systems have increased in the field of clinical drug discovery. Among the many challenges in the drug discovery field, neural drug discovery is one of the hot topics currently being targeted. Neural signal transduction occurs through the synapse. The synapses can be prepared with cultured neuroblast cells and their differentiation. However, it is very difficult to maintain differentiated synapses. This difficulty may increase the range of fluctuation of the data on cultured cell based assay.

We have investigated the problem of the neural cell-based assay. In order to minimize data fluctuation and to perform this assay easily, we have developed a post-synapse model cell [12]. The neural signal is often regulated by regulating receptors on the synapse. The postsynapse function is represented by neural transmitter receptors that are localized on a post-synaptic membrane. The ionotropic glutamate receptor (GluR) is a hot target in the field of neural drug discovery and it is a ligand-gated cation channel which mediates most of the excitatory neurotransmissions in the central nervous system. We have investigated GluR and have employed it in the post-synapse model cell we engineered in our previous study [12]. We suggested that the post-synapse model cell has a GluR function because the post-synapse model cell can be cultivated quickly and is much easier to handle under

${ }^{*}$ Corresponding authors: Prof. Tetsuya Haruyama, Department of Biological Functions and Engineering, Kyushu Institute of Technology, Kitakyushu Science and Research Park, Fukuoka, 808-0196, Japan, Tel: +81-93-695-6065; fax: +8193-695-6065; Email: haruyama@life.kyutech.ac.jp

Received December 01, 2010; Accepted December 29, 2010; Published December 31, 2010

Citation: Tateishi A, Cauchi M, Tanoue C, Migita S, Coleman SK, et al. (2011) Discerning Data Analysis Methods to Clarify Agonistic/Antagonistic Actions on the Ion Flux Assay of Ligand-Gated Ionotropic Glutamate Receptor on Engineered Post-Synapse Model Cells. J Biosens Bioelectron 2:104. doi:10.4172/21556210.1000104

Copyright: $\odot 2011$ Tateishi A, et al. This is an open-access article distributed under the terms of the Creative Commons Attribution License, which permits unrestricted use, distribution, and reproduction in any medium, provided the original author and source are credited. 
Citation: Tateishi A, Cauchi M, Tanoue C, Migita S, Coleman SK, et al. (2011) Discerning Data Analysis Methods to Clarify Agonistic/Antagonistic Actions on the Ion Flux Assay of Ligand-Gated Ionotropic Glutamate Receptor on Engineered Post-Synapse Model Cells. J Biosens Bioelectron 2:104. doi:10.4172/2155-6210.1000104

experimental conditions than cultured neural cells. We were able to conclude from our research that the post-synapse model cell has an advantage when performing smart cell-based assays. However, the individual responses of the post-synapse model cell still contained data fluctuation. The data analysis may promise to solve the fluctuation from individual cellular responses.

The statistical approaches i.e. principal component analysis (PCA) and hierarchical cluster analysis (HCA) can be used to analyze the interrelationships among samples for which a large number of variables have been monitored, and to explain these relationships in terms of their common underlying dimensions known as principal components (PCs) [13-16]. The statistical approach involves finding a way of condensing the information contained in a number of original variables into a smaller set of dimensions with a minimum loss of information. This is achieved by filtering out the noise contained in the dataset without removing the vital information described in the variance of the data. Therefore functional biosensing coupled with the cellular biosensing and these analytical methods may reveal remarkable trends, such as capturing the concentration distribution of the applied chemicals for investigation of cytotoxisity $[16,17]$. This will enable researchers to identify and discriminate the efficacy of medicines simply by combining the principal components analysis (PCA) and the hierarchical cluster analysis (HCA) data analysis method.

In this study, we analyzed data from post-synapse model cell response by chemometorics approaches. The multivariate data analysis methods, PCA and HCA, were employed. The post-synapse model cells with above two analytical methods provided a sodium ion influx profile which is derived by an agonists or antagonists application. The cellular biosensing combined with the data analytical methods, PCA and HCA, enables to develop a smart system to perform practical qualified analysis.

\section{Materials and Methods}

\section{Chemicals}

D-glutamic acid (Glu) and kainic acid (kainate), alphaamino-3-hydroxy-5-methyl-4-isoxazole-propionic acid (AMPA), 6,7-Dinitroquinoxaline-2,3-dione (DNQX), and 2,3-Dioxo-6-nitro1,2,3,4-tetrahydrobenzo quinoxaline-7-sulfonamide (NBQX) were purchased from Wako Chemicals (Tokyo, Japan). The acetoxymethyl form of sodium ion-binding fluorescent indicator (SBFI) was purchased from Invitrogen (Carlsbad, CA, USA). All chemicals were guaranteed experimental grade

\section{Cell culture and transfection}

COS7 cells were cultured in Dulbecco's modified Eagles medium (DMEM) containing 10\% Fetal bovine serum, 100U/ml penicillin and $100 \mu \mathrm{g} / \mathrm{ml}$ streptomycin. Constructed FLAG-epitope-encoded GluR-D $(\Delta 22-402)$ [18] cloned in pIRES2-GFP vector (Clontech Laboratories, Mountain View, CA, USA) was transfected into the COS7 cells using lipofectamine 2000 (Invitrogen). Due to the function of the internal ribosome entry site (IRES) sequence, GluR-D expression was correlated to the cellular fluorescent intensity derived from GFP [12].

\section{Fluorescence measurement of sodium ion flux}

Because GluR-D induces both sodium and calcium influx by agonistic function [19], we decided to use a SBFI. Intracellular sodium ion imaging was performed using the microscopic image analyzing system AQUA COSMOS software (Hamamatsu Photonics, Japan). SBFI-loaded post-synapse model cells were prepared as described previously [12]. The SBFI signals were examined every 10s using epifluorescence microscope (Nikon, Japan). Pictures were collected by an air-cooled CCD camera. Intracellular ion changes in individual cells were obtained after excitation at $340 \mathrm{~nm}$ and $380 \mathrm{~nm}$, and the fluorescence ratio $\left(\mathrm{R}=I_{340 \mathrm{~nm}} / I_{380 \mathrm{~nm}}\right)$ was calculated.

\section{Data analysis by PCA and HCA}

PCA can be derived from a simple equation given in matrix form:

$$
\mathbf{X}=\mathbf{T} \cdot \mathbf{P}+\mathbf{E}
$$

where $\mathrm{X}$ is the sample data matrix (where samples (the regions in the images) are in rows, and variables (time of image acquisition) are in columns), $\mathrm{T}$ is the score matrix (where samples are in rows and PCs are in columns), $\mathrm{P}$ is the loadings matrix (where PCs are in rows, and loadings in columns) and $\mathrm{E}$ is a residual matrix containing the noise filtered out of the sample matrix X (where $\mathrm{E}$ is thus of the same order as $\mathrm{X})$. The key step in PCA is calculating the loadings matrix P. For further information the reader is directed to the excellent PCA paper by Wold et al. [20].

The columns of $\mathrm{T}$ can then be plotted against one another in order to visualize the relationships between the samples. Typically, PC2 (the second column in T) is plotted against PC1 (the first column in $\mathrm{T})$ as these contain the highest amount of variance captured in the data, in other words the most information. These PCA score plots can also assist in determining how repeatable a set of measurements has been or whether there are outlying samples. The rows of $\mathrm{P}$ contain information on the variables which contribute most to the distribution of the samples, thus the PC1 loading (row 1 of P) will indicate which variables (columns in $\mathrm{X}$ ) have contributed strongly to the distribution of the samples in the first column of $\mathrm{T}$ (PC1).

HCA were performed via a two-step process: calculating the distance (Euclidean distance) between every sample; determining how these samples are linked together [21]. In this way, HCA permits larger and more complex datasets to be viewed in an intuitive and graphical way.

PCA and HCA were applied to the fluorescence measurement data matrix which was made up of the calculated ratios in which the rows of the matrix correspond to the samples and the columns correspond to the time. Data analysis was performed with R (v2.8.1). This is a freely available open-source application available for download (www.rproject.org) and contains a plethora of library packages which can also be downloaded and installed for free.

\section{Result and Discussion}

\section{Identifying the dynamic behavior of ion-flux through GluR on the synapse model cell}

In order to investigate the efficacy of chemicals on GluR functionality, we analyzed the ion flux behavior on GluR-D using SBFI, which is a sodium ion indicator in cells. The effects of the applied ligand can be visualized by plotting the fluorescent intensity against the time elapsed thus showing a profile of sodium influx which is derived by an agonist application (Figure 1). The dynamic behaviors appeared to be different respectively, but do seem to contain information about both GluR functionality and ligand efficacy. Individual components of ion flux behavior, including the increased time in relation to intracellular sodium ion concentration $\left(\left[\mathrm{Na}^{+}\right] \mathrm{i}\right)$ or kinetics and total change of $\left[\mathrm{Na}^{+}\right]$ i contain important information such as the binding amount or the affinity of ligand to GluR. The differences in the efficacy of the drugs 
Citation: Tateishi A, Cauchi M, Tanoue C, Migita S, Coleman SK, et al. (2011) Discerning Data Analysis Methods to Clarify Agonistic/Antagonistic Actions on the Ion Flux Assay of Ligand-Gated Ionotropic Glutamate Receptor on Engineered Post-Synapse Model Cells. J Biosens Bioelectron 2:104. doi:10.4172/2155-6210.1000104

Page 3 of 5

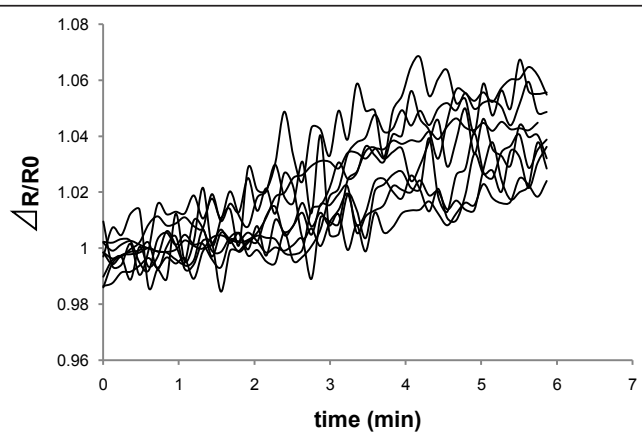

Figure 1: Fluctuated dynamic behaviors of ion flux through GluR on the individual post-synapse model cell upon the application of $2 \mathrm{mM}$ Glu.

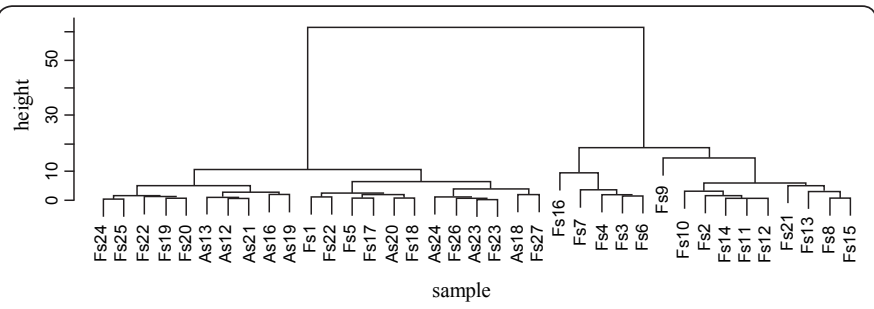

Figure 2: HCA dendrogram for $2 \mathrm{mM}$ Glu (As) and 0mM Glu (Fs). This can identify the sample of non- responding cells. Each sample is described as sample name and number (e.g. As20 mean 0mM Glu applied sample No. 20).
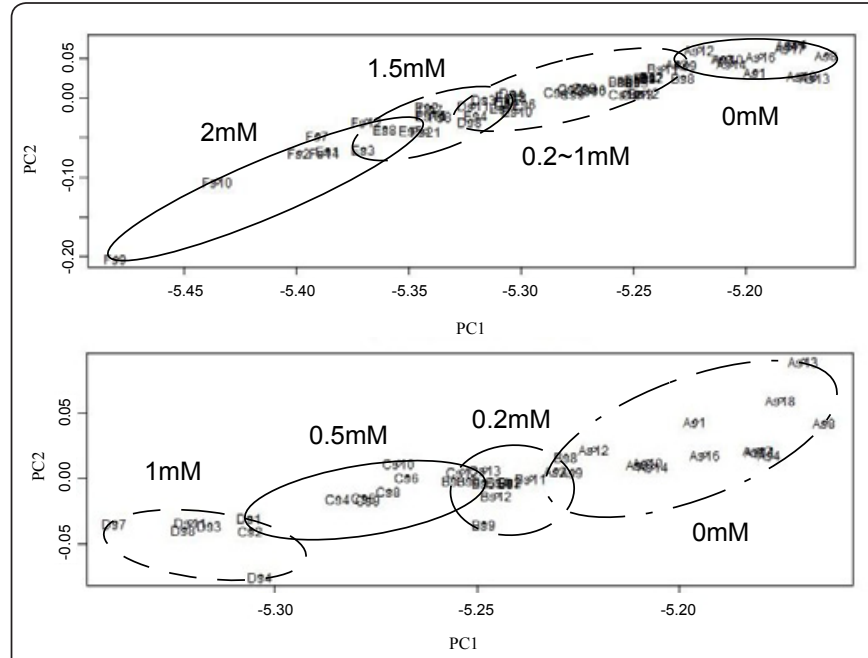

Figure 3: PCA scores plot of ion flux behavior when various concentrations of Glu were applied. (a) Low concentration samples (0 $\mathrm{mM}(\mathrm{As})$ ), middle concentration samples(0.2 mM (Bs), $0.5 \mathrm{mM}(\mathrm{Cs}), 1 \mathrm{mM}$ (Ds)), and high concentration samples (1.5 mM (Es), $2 \mathrm{mM}(\mathrm{Fs}))$ (b) Only low concentration samples and middle concentration samples.

may be reflected in ion flux behavior because differences of drugs may influence not only the total change of $\left[\mathrm{Na}^{+}\right] \mathrm{i}$ but also the kinetics of $\left[\mathrm{Na}^{+}\right] \mathrm{i}$ due to differences of the interaction between GluR and the drugs. Therefore, the ion flux behavior may have similarity depending on the efficacy of the drugs. However, it is difficult to discern the efficacy of the applied drugs from the data of ion flux behavior because the data of ion flux behavior contains multiple variables. Therefore, in order to simplify the data matrix of ion flux behavior and visually access the relationship for each sample, we employed the multivariate data analysis methods of principal components analysis (PCA) and hierarchical cluster analysis (HCA).

\section{Identifying the chemical efficacy from ion flux behavior by HCA and PCA}

In the first step, PCA and HCA were employed to identify the presence of any outlying samples. In general, cell-based assay often contains outliers which are attributed to non-responding cells in the population because some of cells have low viability and are not showing cellular responses. In order to identify outliers, we analyzed the ion flux behavior of $0 \mathrm{mM}$ glutamate (Glu) and the sample of interest by using HCA. Figure 2 shows the HCA dendrogram for $0 \mathrm{mM}$ and $2 \mathrm{mM}$ Gluapplied samples. The HCA dendrogram contained two main clusters. Left cluster contains both $0 \mathrm{mM}$ and $2 \mathrm{mM}$ Glu applied samples, whereas the right cluster was solely dominated by the $2 \mathrm{mM}$ Glu-applied samples. This implies that the $2 \mathrm{mM}$ Glu samples located in the left cluster do not exhibit a cellular response to the applied $2 \mathrm{mM}$ Glu. This means that left cluster in the right cluster may contain some noise in the ion flux behavior. Therefore, HCA has assisted in identifying the presence of outliers.

After removal of the outliers, we attempted to discriminate the Glu concentration dependence of ion flux behavior by using PCA. Figure 3a shows the PCA scores plots of ion flux behavior when various concentrations of Glu are applied. The distribution clearly shows that PC1 has captured the change in Glu concentration as the high concentration samples $(2 \mathrm{mM})$ can be observed in the lower left quadrant, and decreasing successively to $0 \mathrm{mM}$ towards the upper right quadrant. Figure $3 \mathrm{~b}$ shows the PCA scores plot of the ion flux behavior corresponding to the concentration of the applied Glu varying from 0 to $1.0 \mathrm{mM}$. This method can identify tiny differences in concentration. Therefore, PCA can be employed to discriminate the efficacy of chemicals to GluR from dynamic behavior of ion flux.

\section{Agonist analysis by PCA and HCA}

In order to determine the applicability of HCA and PCA analysis in drug evaluation, we analyzed ion flux behavior when GluR agonist, AMPA and kainate, were applied. AMPA is a full-agonist of the AMPA

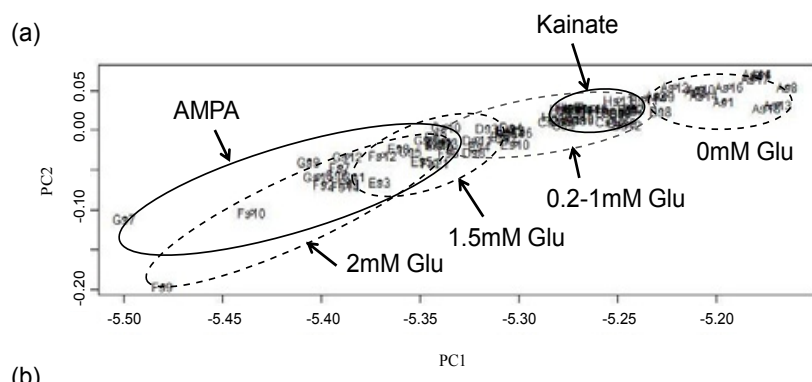

(b)

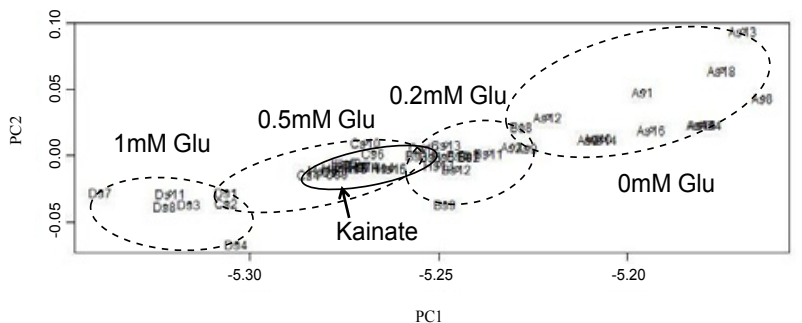

Figure 4: Agonist analysis by PCA. (a) PCA scores plots for various concentration of glutamate and $2 \mathrm{mM}$ AMPA (Gs) and $2 \mathrm{mM}$ kainate $(\mathrm{Hs})$ are combined. (b) PCA plots for only low and middle concentration glutamate and kainate are combined. The area on the clustered PCA plots of Glu samples is indicated by a dotted line and the area of agonist (AMPA, kainate) is indicated by solid line. 
Citation: Tateishi A, Cauchi M, Tanoue C, Migita S, Coleman SK, et al. (2011) Discerning Data Analysis Methods to Clarify Agonistic/Antagonistic Actions on the Ion Flux Assay of Ligand-Gated Ionotropic Glutamate Receptor on Engineered Post-Synapse Model Cells. J Biosens Bioelectron 2:104. doi:10.4172/2155-6210.1000104

Page 4 of 5

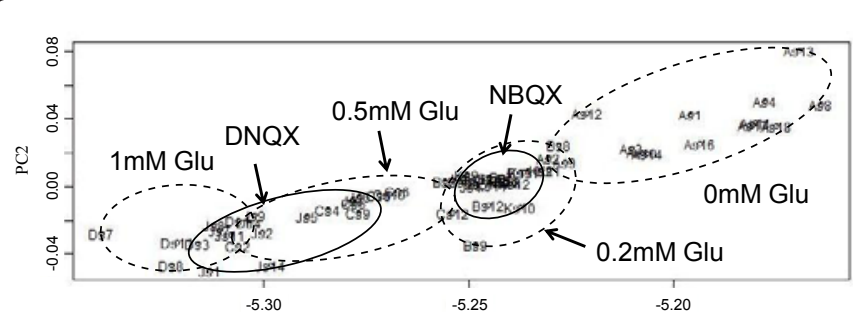

Figure 5: Antagonist analysis by PCA. PCA scores plot for various concentrations of glutamate and 0.05mM DNQX (Js) and 0.05mM NBQX (Ks) combined for antagonist evaluation. The area on the clustered PCA plots of Glu samples is indicated by dotted line and the area of antagonist (NBQX $\mathrm{DNQX}$ ) is indicated by a solid line.

receptor and in this respect is similar to Glu, whereas kainate is a partial agonist $[22,23]$. The outliers were identified by HCA and removed as described previously. Figure $4 \mathrm{a}$ and $4 \mathrm{~b}$ shows the PCA scores plots of the ion flux behavior when GluR agonists, AMPA and kainate are respectively applied. The samples treated with AMPA were located within the $2 \mathrm{mM}$ and $1.5 \mathrm{mM}$ data points of Glu. However, the samples treated with kainate were located within the $0.2 \mathrm{mM}$ and $0.5 \mathrm{mM}$ points of Glu. This suggests that the effects of Glu and AMPA were relatively equal. On the other hand, the kainate agonist induced weak ion flux behavior. As is shown in Figure 4, PCA clearly visualizes the effects of the agonists on GluR from the fluctuated dynamic behavior of cellular responses.

\section{Antagonist analysis by PCA \& HCA}

In order to determine the applicability of HCA and PCA analysis in antagonist evaluation, we analyzed the effect of the major competitive inhibitors of GluR, NBQX and DNQX, on ion flux behavior. The postsynapse model cells were treated with each inhibitor $10 \mathrm{~min}$ before the application of Glu. Then we analyzed the ion flux behavior using SBFI. We removed outliers by analyzing the ion flux behavior after using HCA. We then employed PCA to discriminate the effect of the antagonist on the ion flux behavior of the post-synapse model cell (Figure 5). The data points pertaining to NBQX were located within the $0.2 \mathrm{mM}$ data points of glutamate and those for DNQX were located within the 1 $\mathrm{mM}$ and $0.5 \mathrm{mM}$ data points of glutamate. Therefore these data suggest that NBQX strongly inhibits the ion flux compared with DNQX. It is reported that the selectivity of NBQX for GluR is greater than DNQX [24]. These results suggest that analyzing the ion flux behavior by PCA can lead to information regarding the effects of both the agonists and antagonists being attained. As has been demonstrated in this work, the combined procedure of post-synapse model cells and multivariate data analysis (chemometric) methods, namely PCA and HCA, a remarkable level of molecular information from the data of the cell-based assay can be achieved.

\section{Conclusion}

In this study, we attempted to obtain the information for both GluR functionality and ligand efficacy from the ion flux assay on postsynapse model cells by statistical approaches. In order to consider the fluctuation in cellular response, HCA and PCA were employed to analyze the ion flux behavior. These analytical methods were able to identify and discriminate the efficacy of agonists and antagonists. Therefore, the post-synapse model cell-based assay coupled with PCA and HCA is a powerful tool that can employ to determine the agonistic/ antagonistic roles in the ion flux assay of the ligand-gated ionotropic glutamate receptor. These suggest that cellular biosensing combined with data analysis promise to develop the smart system for qualified analysis.

\section{References}

1. Cohen AA, Geva-Zatorsky N, Eden E, Frenkel-Morgenstern M, Issaeva I, et al. (2008) Dynamic proteomics of individual cancer cells in response to a drug Science 322: 1511-1516.

2. Losick R, Desplan C (2008) Stochasticity and cell fate. Science 320: 65-68.

3. Rausenberger J, Kollmann M (2008) Quantifying origins of cell-to-cell variations in gene expression. Biophys J 95: 4523-4528.

4. Mori T, Murata M, Yoshino T, Nakasono S, Saito F et al. (2009) A stable human progesterone receptor expressing HeLa reporter cell line as a tool in chemical evaluation at the different cell-cycle phases. Toxicol Lett 186: 123-129.

5. Asakawa H, Mochitate K, Haruyama T (2008) Seamless signal transduction from live cells to an NO sensor via a cell-adhesive sensing matrix. Anal Chem 80: 1505-1511.

6. Haruyama T (2006) Cellular biosensing: chemical and genetic approaches Anal Chim Acta 568: 211-216.

7. Tanoue C, Asakawa H, Cauchi M, Bessant C, Ikeno S et al. (2010) Tissular model/sensor seamless system for qualified analysis and its characterization. Biochem Eng J 52: 110-115.

8. Banerjee P, Lenz D, Robinson JP, Rickus JL, Bhunia AK (2008) A novel and simple cell-based detection system with a collagen-encapsulated B-lymphocyte cell line as a biosensor for rapid detection of pathogens and toxins. Lab Invest 88: 196-206.

9. Endo T, Yamamura S, Kerman K, Tamiya E (2008) Label-free cell-based assay using localized surface plasmon resonance biosensor. Anal Chim Acta 614 182-189.

10. Haruyama T, Bongsebandhu-Phubhakdi S, Nakamura I, Mottershead D, Keinänen $\mathrm{K}$ et al. (2003) A biosensing system based on extracellular potentia recording of ligand-gated ion channel function overexpressed in insect cells. Anal Chem 75: 918-921.

11. Feng X, Castracane J, Tokranova N, Gracias A, Lnenicka G et al. (2007) A living cell-based biosensor utilizing G-protein coupled receptors: principles and detection methods. Biosens Bioelectron 22: 3230-3237.

12. Migita S, Tateishi A, Keinänen K, Haruyama T (2010) Engineered synapse model cell: genetic construction and chemical evaluation for reproducible highthroughput analysis. Anal Bioanal Chem 396: 1153-1157.

13. Fend R, Kolk AH, Bessant C, Buijtels P, Klatser PR et al. (2006) Prospects for clinical application of electronic-nose technology to early detection of Mycobacterium tuberculosis in culture and sputum. J Clin Microbiol 44: 20392045.

14. Tønning E, Sapelnikova S, Christensen J, Carlsson C, Winther-Nielsen M et al. (2005) Chemometric exploration of an amperometric biosensor array for fast determination of wastewater quality. Biosens Bioelectron 21: 608-617.

15. Boydston-White S, Romeo M, Chernenko T, Regina A, Miljković M et al. (2006) Cell-cycle-dependent variations in FTIR micro-spectra of single proliferating HeLa cells: principal component and artificial neural network analysis. Biochim Biophys Acta 1758: 908-914.

16. Tanoue C, Asakawa H, Cauchi M, Bessant C, Ikeno S et al. (2010) Tissular model/sensor seamless system for qualified analysis and its characterization. Biochem Eng J 52: 110-115.

17. Liu Q, Cai H, Xu Y, Xiao L, Yang M et al. (2007) Detection of heavy metal toxicity using cardiac cell-based biosensor. Biosensors \& Bioelectronics 22 3224-3229.

18. Pasternack A, Coleman SK, Jouppila A, Mottershead DG, Lindfors $M$ et al (2002) Alpha-amino-3-hydroxy-5-methyl-4-isoxazolepropionic acid (AMPA) receptor channels lacking the N-terminal domain. J Biol Chem 277: 4966249667.

19. Dingledine R, Borges K, Bowie D, Traynelis SF (1999) The glutamate receptor ion channels. Pharmacol Rev 51: 7-61.

20. Wold S, Esbensen K, Geladi P (1987) Principal Component Analysis. Chemometrics and Intelligent Laboratory Systems 2: 37-52. 
Citation: Tateishi A, Cauchi M, Tanoue C, Migita S, Coleman SK, et al. (2011) Discerning Data Analysis Methods to Clarify Agonistic/Antagonistic Actions on the Ion Flux Assay of Ligand-Gated Ionotropic Glutamate Receptor on Engineered Post-Synapse Model Cells. J Biosens Bioelectron 2:104. doi:10.4172/2155-6210.1000104

Page 5 of 5

21. Frank Vogt (2007) Applied Chemometrics for Scientists (Richard G. Brereton). J Chem Educ 84: 1926-null.

22. Keinänen K, Wisden W, Sommer B, Werner P, Herb A et al. (1990) A family of AMPA-selective glutamate receptors. Science 249: 556-560.

23. Patneau DK, Vyklicky L Jr, Mayer ML (1993) Hippocampal neurons exhibit cyclothiazide-sensitive rapidly desensitizing responses to kainate. J Neurosci 13: 3496-3509.

24. Traynelis SF, Wollmuth LP, McBain CJ, Menniti FS, Vance KM (2010) Glutamate receptor ion channels: structure, regulation, and function. Pharmacol Rev 62 : 405-496. 